\title{
Assessment of the Platelet Parameters in Children With Type 1 Diabetes Mellitus
}

\author{
Ozlem Korkmaz
}

\begin{abstract}
Background: The purpose of this study was to assess platelet morphological parameters in children and adolescents with type 1 diabetes mellitus (T1DM) and to determine the factors affecting those parameters.

Methods: A total of 80 children with type 1 diabetes mellitus and 80 healthy control subjects were included in this study. All subjects' platelet parameters including platelet count (PLT), mean platelet volume (MPV), platelet distribution width (PDW) and plateletcrit (PCT) levels were measured. Age at diagnosis, duration of diabetes, and hemoglobin A1c (HbA1c) levels of patients with T1DM were also recorded.

Results: There was no significant difference in PLT, MPV, PDW and PCT values between patients and controls $(\mathrm{P}>0.05)$. PCT and PLT values were higher in patients with poor metabolic control compared to the other cases $(\mathrm{P}=0.002, \mathrm{P}=0.005)$. Positive correlation was found between $\mathrm{HbA1}$ c and PCT $(\mathrm{r}=0.28, \mathrm{P}=0.01)$. There was no correlation between HbA1c and MPV, PDW and PLT.

Conclusions: Indices of platelet morphology such as PCT, PLT, PDW and MPV were similar in children with T1DM and in healthy controls. However, an increase in PCT values in poor glycemic control group and a significant positive correlation between PCT and HbA1c were observed, suggesting that PCT levels may be an early marker of vascular complication.
\end{abstract}

Keywords: Type 1 diabetes mellitus; Children; Plateletcrit; Platelet

\section{Introduction}

Type 1 diabetes mellitus (T1DM) is one of the most common endocrinological disorders in children and adolescents. Its incidence below the age of 14 ranges from $0.1 / 100,000$ to $36.8 / 100,000$ annually, and varies between countries [1]. Microvascular (retinopathy, neuropathy, and nephropathy) and macro-

Manuscript submitted October 30, 2018, accepted November 10, 2018

Department of Pediatric Endocrinology, Adana Training and Research Center, Baskent University Faculty of Medicine, Adana, Turkey.

Email: ozlem-korkmazz@hotmail.com vascular (coronary artery disease, peripheral artery disease, and cerebrovascular disease) atherothrombotic complications may develop in children and adolescents, depending on duration of diabetes, degree of metabolic control, and other factors (such as genetic and smoking). Hyperglycemia, dyslipidemia, inflammation and stress are factors that increase the risk of vascular complications in patients with T1DM. The majority of ischemic events are known to develop due to intravascular thrombosis. Platelet activation plays a key role in the development of atherosclerosis. Type 1 and type 2 diabetes have platelet hyperactivity, dysfunction and changed morphology which lead to thrombus formation, microvascular embolization and discharge of oxidative, constrictive and mitogenic substances, and play a key role in acute coronary events and other thromboembolic diseases [2]. Mean platelet volume (MPV) is a marker of platelet function and activation. MPV and platelet distribution width (PDW) can be used as markers in the early diagnosis of diabetic complications in patients with type 2 diabetes mellitus (T2DM) [3]. Plateletcrit (PCT) levels are defined as an independent marker of vascular changes, particularly in the coronary arteries. The effect of platelet morphological parameters on metabolic control in patients with T1DM is still unclear. Very few studies have evaluated morphological changes in platelets, particularly in children and adolescents with T1DM. The purpose of this study was to assess platelet morphological parameters in children with T1DM and to determine the factors affecting those parameters.

\section{Materials and Methods}

Eighty patients diagnosed with T1DM, age between 3.9 - 17.6 years and followed up by the Pediatric Endocrinology Clinic were included in the study. Patients with a history of drug use, a history of accompanying chronic disease, with findings of current acute infection, or with severe hypoglycemia or diabetic ketoacidosis were excluded. A control group was established consisting of 80 subjects with no history of chronic disease presenting to the pediatric clinic for routine check-up. This study was approved by Baskent University Institutional Review Board. Clinical Investigations Ethical Committee approval was obtained for the study and with the 1964 Helsinki Declaration and its later amendments or comparable ethical standards.

\section{Data collection}

All subjects' anthropometric parameters (weight, weight stand- 
Table 1. Clinical Characteristics of the Study and Control Groups

\begin{tabular}{llll} 
& Type 1 DM & Control & P values \\
\hline Age & $11.41 \pm 3.79$ & $10.61 \pm 2.86$ & 0.134 \\
Gender ratio (boys/girls) & $41 / 39$ & $38 / 42$ & 0.752 \\
Weight SDs & $0.01 \pm 1.16$ & $0.06 \pm 1.47$ & 0.738 \\
Height SDs & $-0.13 \pm 1.22$ & $0.08 \pm 1.46$ & 0.297 \\
BMI SDs & $0.12 \pm 1.03$ & $0.17 \pm 1.31$ & 0.751 \\
Diabetes duration & $3.91 \pm 2.76$ & & \\
HbA1c & $9.11 \pm 1.64$ & & \\
\hline
\end{tabular}

Type 1 DM: type 1 diabetes mellitus; SDs: standard deviation score; BMI: body mass index; HbA1c: hemoglobin A1c.

ard deviation score (SDs), height, height SDs, body mass index (BMI) and BMI SDs) and platelet count (PLT), MPV, PDW, PCT levels were recorded. Age at diagnosis, duration of diabetes, and hemoglobin A1c (HbA1c) levels of patients with T1DM were also obtained. Anthropometric data were converted to standard deviation scores using Turkish standard data [4]. BMI was calculated using the standard formula weight $/$ height $^{2}$ $\left(\mathrm{kg} / \mathrm{m}^{2}\right)$. Type $1 \mathrm{DM}$ patients were also stratified according to good $(n=14)$, moderate $(n=30)$ and poor metabolic control $(n$ $=36$ ) which were defined as: HbAlc $<7.5 \%, 7.5-9 \%$ and $>9 \%$ respectively. Target HbA1c levels of $<7.5 \%$, based on ADA/ IDF/ISPAD recommendations [5].

\section{Laboratory analyses}

Blood samples were processed within $2 \mathrm{~h}$ after collection, according to the standard operating procedure of our institution. Platelets morphology parameters, e.g. PLT, MPV, PDW and PCT were extracted from routinely performed complete blood count results. The blood counts were performed with flow cytometry peroxidase methodology-based analyses (Siemens Advia 2020i, Ireland). HbA1c was measured using the spectrophotometric methods. HbAlc measurements were performed with the Siemens Advia 1800 Chemistry System (Japan).

\section{Statistical analysis}

Statistical evaluation was performed by statistical package SPSS version 17(SPSS Inc, Chicago, IL). Data were expressed

Table 2. Platelet Parameters of the Study and Control Group as mean \pm standard deviation. The parameters with normal distribution were compared within two groups using Student's $t$-test, whereas the parameters with non-normal distribution were compared within the two groups using the Mann-Whitney U test. Pearson's correlation analysis was used to assess the relationships between the parameters that showed normal distribution and Spearman's rho correlation analysis was performed to analyse the relationships between the parameters that did not show normal distribution. Spearman's rho correlation test was used for the comparisons of categorical variables and correlations among two variables. Kruskal-Wallis test which is a nonparametric test was used for the comparison of multiple groups. A P value $<0.05$ was considered statistically significant.

\section{Results}

The mean age of enrolled subjects was $11.41 \pm 3.79$ years (range: 3.9 - 17.6 years) with mean duration of T1DM of 3.91 \pm 2.76 years (range: 0.6 - 15 years). Age at diagnosis was 7.64 \pm 3.49 years. The study and control groups did not differ in terms of sex and age. The basal characteristics of the study groups were shown in Table 1.

There was no significant difference in PCT, PLT, PDW and MPV values between patients and controls $(\mathrm{P}>0.05)(\mathrm{Ta}-$ ble 2).

\section{Influence of metabolic control on platelet morphology in- dices}

Patients were divided into three groups according to HbA1c levels (HbA1c $<7.5 \%, 7.5-9 \%$ and $>9 \%$ ), PCT and PLT values were higher in patients with poor metabolic control compared to the other cases $(\mathrm{P}=0.002, \mathrm{P}=0.005)$. There was no statistically significant difference between the degree of metabolic control and MPV and PDW levels ( $\mathrm{P}>0.05)$.

\section{Correlation of platelet indices with various disease-related factors}

There was no correlation between duration of diabetes and MPV, PDW, PCT and PLT. Positive correlation was found between $\mathrm{HbAlc}$ and PCT $(\mathrm{r}=0.28, \mathrm{P}=0.01)$. There was no correlation between $\mathrm{HbA} 1 \mathrm{c}$ and MPV, PDW and PLT (Table 3).

\begin{tabular}{llll} 
& Type 1 DM (Mean \pm SD) & Control (Mean \pm SD) & P values \\
\hline PLT $\left(10^{3} / \mu \mathrm{L}\right)$ & $315.20 \pm 62.81$ & $315.98 \pm 57.56$ & 0.747 \\
MPV (fL) & $8.35 \pm 1.06$ & $8.13 \pm 0.57$ & 0.112 \\
PDW (\%) & $45.65 \pm 6.64$ & $44.16 \pm 4.79$ & 0.083 \\
PCT (\%) & $0.26 \pm 0.06$ & $0.25 \pm 0.04$ & 0.833 \\
\hline
\end{tabular}

Type 1 DM: type 1 diabetes mellitus; PLT: platelet; MPV: mean platelet volume; PDW: platelet distribution width; PCT: plateletcrit. 


\section{Discussion}

Diabetes has been proved to be a prothrombotic condition. Platelets are cell fragments that play an active role in the development of atherosclerosis and acute complications [6]. Large platelets are more active, contain more secretory granules, and produce more serotonin beta thromboglobulin and thromboxane A2, which support platelet aggregation. This is regarded as a mechanism that accounts for platelet hyperactivity and thus their effects on thrombosis [7, 8]. MPV is a direct marker of platelet activity and function [9]. Studies have determined higher MPV in individuals with both T1DM and T2DM, and these changes have been linked to metabolic control $[10,11]$. Sharpe et al [11] determined a significant increase in MPV values in patients with T1DM compared to healthy controls. Venkatesh et al [12] determined a significant increase in MPV values in subjects with childhood T1DM compared to a control group. Various different studies have thus suggested that platelets can be used as a marker for predicting an increase in the risk of the micro- and macrovascular complications of diabetes [13-15]. However, Ersoy et al [16] reported similar MPV values in children diagnosed with T1DM to those in a control group ( $8.74 \pm 0.96$ and $8.49 \pm 0.66$, respectively), although correlation was determined between intima-media thickness and MPV values. Similarly, in our study, we determined no statistically significant difference in MPV values between children with T1DM and the control group. This may be explained in terms of the hypothesis that metabolic imbalance in diabetic cases does not yet lead to changes in MPV values in the early period due to the short duration of the disease in childhood.

Different results have been reported in studies assessing platelet counts in diabetic patients. Platelet activation and aggregation resulting from an overreaction to endogenous agonists in diabetic patients can lead to depletion of platelets in the circulation. Some studies support the idea that ineffective thrombopoiesis in diabetic subjects leads to a low platelet count [17, 18]. Hekimsoy et al [19] also observed a lower platelet count in diabetic cases. They suggested that this might also be related to differences in platelet production and turnover in cases of T2DM. Pirgon et al [20] determined no significant difference in platelet numbers between children with T1DM and controls $\left(333.7 \pm 71.3 \times 10^{9} / \mathrm{L}\right.$, and $339.6 \pm 101.9 \times$ $10^{9} / \mathrm{L}$, respectively). Another study of T2DM patients reported a higher platelet count in the diabetic group than in the control group, although the difference was not statistically significant. A different study involving adult patients with T1DM determined a higher platelet count in diabetics than in the control group, and observed positive correlation with poor metabolic control [21]. Reactive thrombocytosis associated with increasing blood glucose levels has been reported in diabetic patients with poor metabolic control. An increasing platelet count has been described as a possible response to stress, and to be capable of increasing the risk of vascular complications by damaging the microcirculation. In the present study, we determined no difference in platelet counts between children with T1DM and the control group. However, we observed a higher platelet count in cases with poor metabolic control $(\mathrm{HbAl}>>9 \%)$ than in the other groups $(\mathrm{P}=0.005)$.

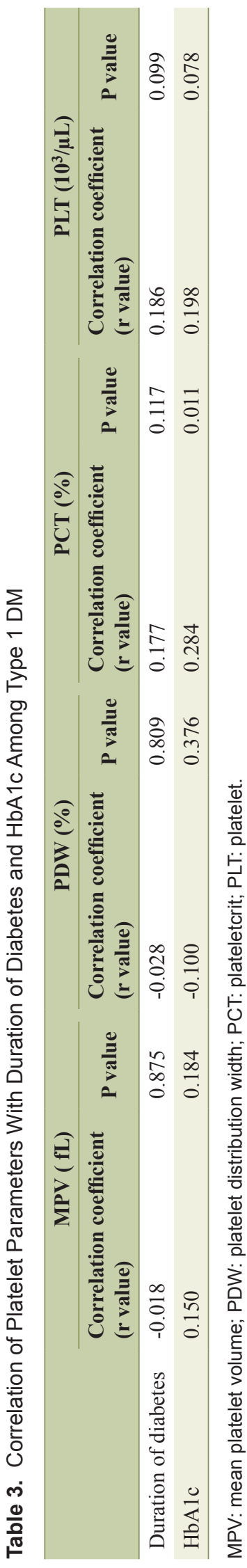


Vagdatli et al [22] in their study determined that PDW levels can be used as a specific marker of platelet activation. Malachowska et al [23] determined an increase in PDW values in cases of T1DM compared to a control group. This large study of adults with T2DM reported that duration of diabetes was positively correlated with PDW and MPV. That study also reported positive correlation between PDW and HbA1c [3]. We observed no statistically significant difference in PDW between our study groups. No correlation was also observed between $\mathrm{HbA} 1 \mathrm{c}$ levels and PDW $(\mathrm{r}=-0.10, \mathrm{P}=0.376)$. Previous studies have shown correlation between duration of diabetes and increasing MPV values [24], although others do not support this [13]. No relation between duration of diabetes and MPV was observed in our study.

PCT is assumed to show the number of platelets in circulation in one unit volume, and expresses platelet variation and heterogeneity [25]. There have been few studies of PCT values in diabetic cases, although Venkatesh et al [12] found no significant difference in terms of PCT values between children diagnosed with T1DM and a control group. Another study of patients with T2DM determined higher PCT values than in a control group. That study also determined higher PCT values in the presence of chronic complications. This finding was attributed to an increase in platelet mass, and thus in PCT, since platelets in diabetic patients are larger and more reactive [26]. In our study, however, we determined no difference in PCT between the T1DM patient group and the control group.

Hyperglycemia results in non-enzymatic glycosylation of proteins on the platelet surface, and therefore results in a decrease in membrane fluidity and an increase in platelet reactivity. A few studies have investigated relations between metabolic control and platelet morphological parameters in children with T1DM. A retrospective study from 2015 involving 4,072 patients reported a positive relationship between $\mathrm{HbA1}$ c levels and MPV [27]. Malachowska et al [23] observed no significant relation between MPV and $\mathrm{HbA1C}$. Zaccardi et al [28] observed a significant change in MPV-platelet count in cases with poor metabolic control (HbAlc $>9 \%$ ) compared to other cases. Another large study of adults with T2DM reported significant positive correlation between $\mathrm{HbA} 1 \mathrm{c}$ levels and MPV [29]. Although Pirgon et al [20] observed higher MPV in cases with T1DM compared to a control group; they determined no significant correlation between MPV and $\mathrm{HbA} 1 \mathrm{c}$, BMI or age. Demirtunc et al [30] reported significantly higher MPV in patients with $\mathrm{HbA} 1 \mathrm{c}$ values $>7 \%$ compared to those with $\mathrm{HbA} 1 \mathrm{c}$ $\leq 7 \%$. In our study, positive correlation was found between HbAlc and PCT. The PCT values were higher in cases with poor metabolic control. This finding supports the idea that PCT values can be used as a marker in determining the risk of future complications, particularly in individuals with poor metabolic control. PCT may be an early marker of vascular damage in these cases.

There are a number of limitations to our study. In particular, metabolic control was determined only on the basis of $\mathrm{HbA} 1 \mathrm{c}$ levels. However, greater glycemic variability is regarded as an independent risk factor in the development of vascular complications of diabetes [31]. Use of continuous glucose measurement systems in these cases might therefore have increased the power of our study.

\section{Conclusions}

Indices of platelet morphology such as MPV, PDW, PCT and PLT were similar in children with T1DM and in healthy controls. This may be associated with young age and a short duration of diabetes. However, an increase in PCT values in poor glycemic control group and a significant positive correlation between PCT and HbAlc were observed, suggesting that PCT levels may be an early marker of vascular complication. Since PCT analysis is simple and inexpensive, it can be employed as a simple prognostic method for determining the risk of diabetic complications. Further long-term prospective studies with larger patient series are now needed on this subject.

\section{Conflict of Interest}

The author declares that there is no conflict of interest.

\section{Financial Support}

None.

\section{References}

1. Karvonen M, Viik-Kajander M, Moltchanova E, Libman I, LaPorte R, Tuomilehto J. Incidence of childhood type 1 diabetes worldwide. Diabetes Mondiale (DiaMond) Project Group. Diabetes Care. 2000;23(10):1516-1526.

2. Kakouros N, Rade JJ, Kourliouros A, Resar JR. Platelet function in patients with diabetes mellitus: from a theoretical to a practical perspective. Int J Endocrinol. 2011;2011:742719.

3. Sharma M, Narang S, Nema SK. Study of altered platelet morphology with changes in glycaemic status. Int J Res Med Sci. 2016;4(3):757-761.

4. Bundak R, Furman A, Gunoz H, Darendeliler F, Bas F, Neyzi O. Body mass index references for Turkish children. Acta Paediatr. 2006;95(2):194-198.

5. Chiang JL, Kirkman MS, Laffel LM, Peters AL, Type 1 Diabetes Sourcebook A. Type 1 diabetes through the life span: a position statement of the American Diabetes Association. Diabetes Care. 2014;37(7):2034-2054.

6. Arikanoglu A, Yucel Y, Acar A, Cevik MU, Akil E, Varol $\mathrm{S}$. The relationship of the mean platelet volume and $\mathrm{C}$ reactive protein levels with mortality in ischemic stroke patients. Eur Rev Med Pharmacol Sci. 2013;17(13):17741777.

7. Martin JF, Bath PM, Burr ML. Influence of platelet size on outcome after myocardial infarction. Lancet. 1991;338(8780):1409-1411.

8. D'Erasmo E, Aliberti G, Celi FS, Romagnoli E, Vecci E, Mazzuoli GF. Platelet count, mean platelet volume and their relation to prognosis in cerebral infarction. J Intern Med. 1990;227(1):11-14.

9. Chu SG, Becker RC, Berger PB, Bhatt DL, Eikelboom 
JW, Konkle B, Mohler ER, et al. Mean platelet volume as a predictor of cardiovascular risk: a systematic review and meta-analysis. J Thromb Haemost. 2010;8(1):148-156.

10. Glassman AB. Platelet abnormalities in diabetes mellitus. Ann Clin Lab Sci. 1993;23(1):47-50.

11. Sharpe PC, Trinick T. Mean platelet volume in diabetes mellitus. Q J Med. 1993;86(11):739-742.

12. Venkatesh V, Kumar R, Varma DK, Bhatia P, Yadav J, Dayal D. Changes in platelet morphology indices in relation to duration of disease and glycemic control in children with type 1 diabetes mellitus. J Diabetes Complications. 2018;32(9):833-838.

13. Kodiatte TA, Manikyam UK, Rao SB, Jagadish TM, Reddy M, Lingaiah HK, Lakshmaiah V. Mean platelet volume in Type 2 diabetes mellitus. J Lab Physicians. 2012;4(1):5-9.

14. Zuberi BF, Akhtar N, Afsar S. Comparison of mean platelet volume in patients with diabetes mellitus, impaired fasting glucose and nondiabetic subjects. Singapore Med J. 2008;49(2):114-116.

15. Ates $\mathrm{O}$, Kiki I, Bilen $\mathrm{H}$, et al. Association of mean platelet volume with the degree of retinopathy in patients with diabetes mellitus. Eur J Gen Med. 2009;6(2):99-102.

16. Ersoy M, Selcuk Duru HN, Elevli M, Ersoy O, Civilibal M. Aortic intima-media thickness and mean platelet volume in children with type 1 diabetes mellitus. Iran J Pediatr. 2015;25(2):e368.

17. Kim JH, Bae HY, Kim SY. Clinical marker of platelet hyperreactivity in diabetes mellitus. Diabetes Metab J. 2013;37(6):423-428.

18. Tschope D, Langer E, Schauseil S, Rosen P, Kaufmann L, Gries FA. Increased platelet volume - sign of impaired thrombopoiesis in diabetes mellitus. Klin Wochenschr. 1989;67(4):253-259.

19. Hekimsoy Z, Payzin B, Ornek T, Kandogan G. Mean platelet volume in Type 2 diabetic patients. J Diabetes Complications. 2004;18(3):173-176.

20. Pirgon O, Tanju IA, Erikci AA. Association of mean platelet volume between glucose regulation in children with type 1 diabetes. J Trop Pediatr. 2009;55(1):63-64.

21. Uko EK, Erhabor O, Isaac IZ, et al. Some haematological parameters in patients with type-1 diabetes in Sokoto, North Western Nigeria. J Blood Lymph. 2013;3:1.
22. Vagdatli E, Gounari E, Lazaridou E, Katsibourlia E, Tsikopoulou F, Labrianou I. Platelet distribution width: a simple, practical and specific marker of activation of coagulation. Hippokratia. 2010;14(1):28-32.

23. Malachowska B, Tomasik B, Szadkowska A, Baranowska-Jazwiecka A, Wegner O, Mlynarski W, Fendler W. Altered platelets' morphological parameters in children with type 1 diabetes - a case-control study. BMC Endocr Disord. 2015;15:17.

24. Buch A, Kaur S, Nair R, Jain A. Platelet volume indices as predictive biomarkers for diabetic complications in Type 2 diabetic patients. J Lab Physicians. 2017;9(2):8488.

25. Akpinar I, Sayin MR, Gursoy YC, Aktop Z, Karabag T, Kucuk E, Sen N, et al. Plateletcrit and red cell distribution width are independent predictors of the slow coronary flow phenomenon. J Cardiol. 2014;63(2):112-118.

26. Alhadas KR, Santos SN, Freitas MS, et al. Are platelet indices useful in the evaluation of type 2 diabetic patients? Brazilian Journal of Pathology and Laboratory Medicine. 2016;52:2.

27. Lippi G, Salvagno GL, Nouvenne A, Meschi T, Borghi $\mathrm{L}$, Targher G. The mean platelet volume is significantly associated with higher glycated hemoglobin in a large population of unselected outpatients. Prim Care Diabetes. 2015;9(3):226-230.

28. Zaccardi F, Rocca B, Rizzi A, Ciminello A, Teofili L, Ghirlanda G, De Stefano V, et al. Platelet indices and glucose control in type 1 and type 2 diabetes mellitus: A case-control study. Nutr Metab Cardiovasc Dis. 2017;27(10):902-909.

29. Shah B, Sha D, Xie D, Mohler ER, 3rd, Berger JS. The relationship between diabetes, metabolic syndrome, and platelet activity as measured by mean platelet volume: the National Health And Nutrition Examination Survey, 1999-2004. Diabetes Care. 2012;35(5):1074-1078.

30. Demirtunc R, Duman D, Basar M, Bilgi M, Teomete M, Garip T. The relationship between glycemic control and platelet activity in type 2 diabetes mellitus. J Diabetes Complications. 2009;23(2):89-94.

31. Brownlee M, Hirsch IB. Glycemic variability: a hemoglobin A1c-independent risk factor for diabetic complications. JAMA. 2006;295(14):1707-1708. 